\title{
Conf $-940711-12$
}

UCRL-JC-115807

PREPRINT

\section{A New Comprehensive Reaction Mechanism for Combustion of Hydrocarbon Fuels}

MAK 211994

\author{
E. Ranzi, A. Sogaro, P. Gaffuri and G. Pennati \\ OSTI \\ Dipartimento di Chimica Industriale ed Ingeneria Chimica \\ Politecnico di Milano, Milano, Italy
}

\author{
C.K. Westbrook and W.J. Pitz
}

Lawrence Livermore National Laboratory

Livermore, CA 94550

This paper was prepared for submittal to the Twenty-Fifth International Symposium on Combustion

UC Irvine, Irvine, CA July 31- Aug 5, 1994

December 3, 1993

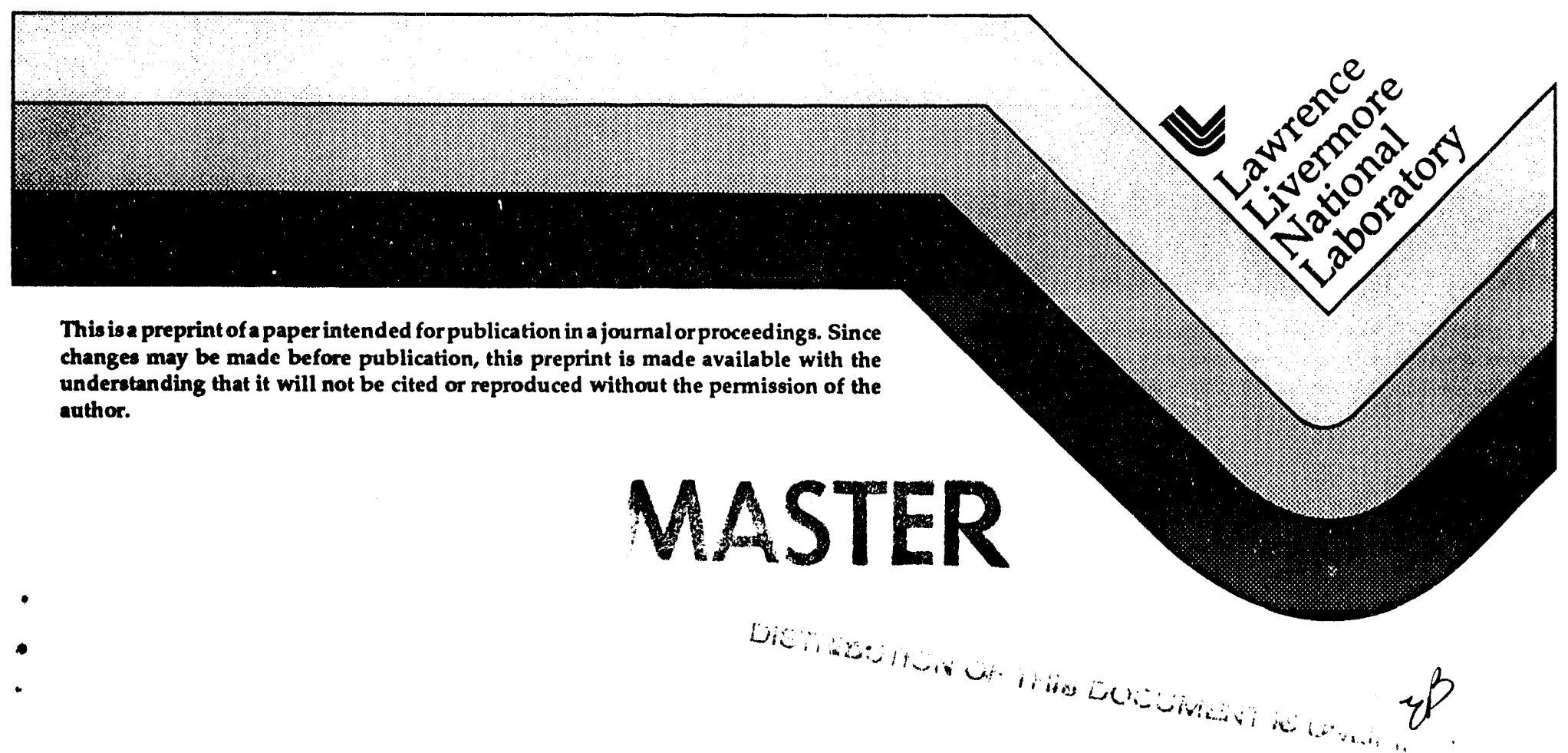




\section{DISCLAIMER}

This document was prepared as an account of work sponsored by an agency of the United States Government. Neither the United States Government nor the University of California nor any of their employees, makes any warranty, express or implied, or assumes any legal liability or responsibility for the accuracy, completeness, or usefulness of any information, apparatus, product, or process disclosed, or represents that its use would not infringe privately owned rights. Reference herein to any specific commercial products, process, or service by trade name, trademark, manufacturer, or otherwise, does not necessarily constitute or imply its endorsement, recommendation, or favoring by the United States Government or the University of California. The views and opinions of authors expressed herein do not necessarily state or reflect those of the United States Government or the University of California, and shall not be used for advertising or product endorsement purposes. 


\author{
A New Comprehensive Reaction Mechanism \\ for Combustion of Hydrocarbon Fuels \\ E. Ranzi, A. Sogaro, P. Gaffuri, and G. Pennati \\ Dipartimento di Chimica Industriale ed Ingegneria Chimica \\ Politecnico di Milano, Milano, Italy \\ and \\ C. K. Westbrook and W. J. Pitz \\ Lawrence Livermore National Laboratory \\ Livermore, CA 94550 USA
}

\begin{abstract}
A detailed chemical kinetic model has been developed which accurately describes pyrolysis, ignition and oxidation of many small hydrocarbon fuels over a wide range of experimental conditions. Fuels include carbon monoxide and hydrogen, methane and other alkane species up to n-butane, ethylene, propene, acetylene, and oxygenated species such as methanol, acetaldehyde and ethanol. Formation of some larger intermediate and product species including benzene, butadiene, large olefins, and cyclopentadiene has been treated in a semi-empirical manner. The reaction mechanism has been tested for conditions that do not involve transport and diffusional processes, including plug flow and stirred reactors, batch reactors and shock tubes. The present kinetic model and its validation differ from previous comprehensive detailed reaction mechanisms in two important ways. First, in addition to conventional combustion data, experiments more commonly associated with chemical engineering problems such as oxidative coupling, oxidative pyrolysis and steam cracking are used to test the reaction mechanism, making it even more general than previous models. In addition, $\mathrm{H}$ atom abstraction and some other reaction rates, even for the smaller $\mathrm{C}_{2}, \mathrm{C}_{3}$ and $\mathrm{C}_{4}$ species, are treated using approximations that facilitate future extensions to larger fuels in a convenient manner. The construction of the reaction mechanism and selected comparisons with experimental data are described that illustrate the generality of the model.
\end{abstract}




\section{Introduction}

Over the past 20 years, kinetic modeling has emerged as a powerful and useful tool in the analysis $c$. ombustion problems. Used in combination with theoretical and experimental techniques, numerical modeling of combustion chemistry has been used to establish elementary reaction rates, product distributions, energy release, combustion efficiency and other important fundamental chemical combustion parameters. Perhaps even more significant, computer models including detailed chemical kinetic reaction mechanisms have contributed to the understanding and solution of many long-standing practical combustion problems, including flame quenching on internal combustion engine chamber walls [1], soot production in engines [2], and engine knock [3]. Further applications of detailed kinetic modeling to address important combustion problems have included many advances directed towards reduction of emissions of oxides of nitrogen $\left(\mathrm{NO}_{\mathbf{X}}\right)$ from combustors [4].

A more recent advance has been the application of kinetic modeling to a wide variety of chemical engineering problems, including subjects such as steam cracking, olefin production and pyrolysis, oxidative coupling and a range of other chemical processes. Many of these chemical engineering applications have been discussed by Dente et al. [5] and Ranzi et al. [6], and there is clearly an immense area of common interest between the combustion and chemical engineering applications of detailed chemical kinetic modeling. Many chemical engineering applications occur at temperatures that are the same as those which are important for slow oxidation processes and engine knock that are central problems for combustion. Many other examples of this overlap can easily be identified; for example, industrial processes that are intended to produce olefins for product manufacturing have exact analogs in combustion ignition problems where olefins are produced during the autoignition of larger hydrocarbon fuels and the conversion of those olefin intermediates to water and carbon dioxide determines whether or not the fuel will ignite.

The present study describes a single reaction mechanism that is used to examine chemical problems from both these fields, and the generally excellent results for both classes of problems indicate that the fundamental kinetic processes are exactly the same, regardless of the details of the application. The same principles are used in developing reaction mechanisms, the same overall temperature ranges, pressures, and fuels are encountered in both types of problems, and the limitations of modeling techniques for both fields are generally the same. 
Structure of the Reaction Mechanism

Detailed reaction mechanisms for hydrocarbon fuels are built in a strongly hierarchical manner [7], in which submechanisms for $\mathrm{H}_{2}$ and $\mathrm{CO}$ oxidation form the core of the overall reaction mechanism. These submechanisms are tested independently, and additional elementary reactions and chemical species are systematically incorporated as the complexity of the fuels dictate. In this way, reactions for formaldehyde $\left(\mathrm{CH}_{2} \mathrm{O}\right)$, methanol $\left(\mathrm{CH}_{3} \mathrm{OH}\right)$, ethane $\left(\mathrm{C}_{2} \mathrm{H}_{6}\right)$, ethylene $\left(\mathrm{C}_{2} \mathrm{H}_{4}\right)$, acetylene $\left(\mathrm{C}_{2} \mathrm{H}_{2}\right)$, acetaldehyde $\left(\mathrm{CH}_{3} \mathrm{CHO}\right)$, and then $\mathrm{C}_{3}$ and larger species were added sequentially to the $\mathrm{CO}-\mathrm{H}_{2}-\mathrm{O}_{2}$ base mechanism. At each step, the new reactions and species are tested thoroughly by means of comparisons with experimental data, to ensure that the new features are accurate and complete.

A second essential feature in developing comprehensive reaction mechanisms involves testing them against measured data from a variety of experimental systems, with as wide a range in operational parameters as possible, particularly in pressure, temperature, and fuel-oxidizer ratio. The intent is that by comparing experimental and model results over many types of experiments and fuels, the resulting reaction mechanism will be as generally applicable as possible. This approach has been employed widely in developing useful modeling tools for use in combustion system analysis [7]. When a comprehensive mechanism is available for a given fuel, it is often possible to use the mechanism to extrapolate to experimental conditions that may not have been studied explicitly, with much greater confidence than if the reaction mechanism were less thoroughly validated.

As reaction mechanisms are steadily extended to larger and more practical hydrocarbon fuel molecules, for which fewer specific kinetic data are generally available, there is considerable motivation to be able to generate the reaction mechanisms for the larger fuels using automatic algorithms $[5,8]$. This requires algorithms for providing specific reaction rates for all possible classes of reactions, and the present paper, togethe: with preceding work of some of the authors $[5,6,9]$, provides algorithms for a wide variety of fuel types and reactions.

A unique feature of the present model is that, unlike most previous comprehensive mechanisms, it includes validations with lower temperature combustion and additional chemical engineering environments that had not been considered previously. When these features are included, together with more conventional combustion tests at higher temperatires used in earlier comprehensive mechanisms, the resulting model is even more generally valid than others available in the past. 
The detailed submechanisms for $\mathrm{CO}, \mathrm{H}_{2}, \mathrm{CH}_{4}$, and the $\mathrm{C}_{2}$ hydrocarbons are based closely on work done by a considerable number of modeling researchers [7,9-11] and their essential features have been well established. Due to length limitations for this paper, it is not possible to reproduce the entire mechanism here. The details of the mechanism and the rate parameters are summarized in a previous publication [9]; in addition, the entire mechanism can be obtained directly from the present authors in printed media or on electronic disk. For convenience, in the following discussions, when we use reaction numbers to refer to specific reactions, those numbers will indicate reaction numbers in the previous modeling study [9]. The basic mechanism includes some 432 reactions, to which generalized $\mathrm{H}$ atom abstraction reactions are added as will be discussed next.

A major goal of the present modeling effort is to provide a reaction mechanism extendable to larger fuels as the need occurs. Therefore, we have attempted to develop means to extend the mechanism to whatever level of fuel complexity is needed. The most important reactions involving larger practical hydrocarbon fuels are those abstracting $\mathrm{H}$ atoms, the thermal decomposition of the alkyl radicals, and other generic reactions. The present reaction mechanism has developed a formalism for estimating these reaction rates; in many cases this procedure is necessary because the rates have never been measured experimentally. In order to test the concept, the same formalism has been used in this mechanism even in those cases where experimental reaction rate data were available, such as in the cases of methane, ethane and propane. An indication of the validity of the present approach is given by the fact that the present model gives generally good agreement with experimental results for all of the fuels studied.

In Table I the 30 radical species are listed which can abstract $H$ atoms from the various fuels, together with baseline rate expressions for abstraction. These rate expressions are then corrected to reflect two additional factors, the multiplicity or number of similar $\mathrm{H}$ atoms in the fuel (e.g., 4 equivalent $\mathrm{H}$ atoms in methane or 2 equivalent secondary $\mathrm{H}$ atoms in propane), and a second correction to reflect the type of $\mathrm{H}$ atom site in the fuel. These site-specific corrections have been divided into 10 different groups as follows: (0) primary $\mathrm{C}-\mathrm{H}$ bond, (1) secondary $\mathrm{C}-\mathrm{H}$ bond, (2) tertiary $\mathrm{C}-\mathrm{H}$ bond, (3) $\mathrm{H}-\mathrm{H}$ bond, (4) $\mathrm{C}-\mathrm{H}$ bond in methane, (5) $\mathrm{O}-\mathrm{H}$ bond in water, (6) $\mathrm{O}-\mathrm{H}$ bond in $\mathrm{H}_{2} \mathrm{O}_{2}$, (7) vinylic $\mathrm{C}-\mathrm{H}$ bond, (8) aldehydic $\mathrm{C}-\mathrm{H}$ bond, and (9) $\mathrm{O}-\mathrm{H}$ bond in methanol and other alcohols. The correction factors associated with each of these groups are listed in Table II. Using the data from these Tables, it is straightforward to construct $\mathrm{H}$ atom abstraction rates from virtually any type of fuel with reasonable accuracy, as the computed results described below and in Reference [9] demonstrate. 
Some mechanistic simplifications have been included in the present model. Isomers of some larger species are lumped together as a composite species, such as isomers of butene, which include 1-butene, cis-2-butene and trans-2-butene. Similarly, c3h4 isomers are lumped together. In order for these combining practices to be useful, reactions of lumped species must reflect reactions of all isomers, including rates and product distributions of each isor ner. In addition, although the present mechanism includes formation of cyclo- $\mathrm{C}_{5}$ sf ecies, comparable cyclo- $\mathrm{C}_{6}$ species are not included.

Production of heavier hyd.ocarbon species, including aromatic and liquid fuels, is simulated by lumping together constituents at a level that is generally above that which affects the rates of kinetic processes. This combines polyacetylenes, polyaromatics, and related species, and it also combines kinetic processes of aromatic species into a small group of kinetic processes. As long as the fuels of interest remain in the $\mathrm{C}_{1}-\mathrm{C}_{3}, r \mathrm{C}_{4}$ class, this approach will generally be satisfactory, but it will begin to fail as the fuels of interest become comparable in size to the aromatic and related fuels. At this time, it will become necessary to refine or completely replace the heavier hydrocarbon submodels in the present mechanisms.

\section{Model Applications}

To test the present reaction mechanism and its basic philosophy, it is necessary to compare its computed results with selected experimental results. In order to ensure that the mechanism is as widely applicable as possible, it is important to select a broad range of applications with different initial conditions, environments, fuels, and boundary conditions. To test the model, the mechanism has been tested against experimental data in the following specific areas:

1. CO oxidation

2. methane pyrolysis

3. autoignition and oxidation of methane

4. partial oxidation of methane to methanol

5. oxidation of methanol

6. oxidation of formaldehyde

7. ethane pyrolysis

8. ethylene pyrolysis

9. ethane oxidation

10. ethylene oxidation

11. acetaldehyde oxidation

12. C1-C4 ignition 
13. methanol ignition

Each class of applications examines one or more different sets of conditions. Below, some of the results of these comparisons will be summarized. It is not possible to examine each topic in great detail, due to the limitations in the length of the present paper, but several of these will be described in greater detail to illustrate the features of the mechanism and its utility.

\section{Mechanism Tests and Validation}

\section{CO Oxidation}

Many recent modeling studies have established the essential features of the core $\mathrm{CO}-\mathrm{H}_{2}-\mathrm{O}_{2}$ submechanism. Since this is the heart of a comprehensive reaction mechanism, it is essential to ensure that it is accurate and applicable to all the combustion environments to be encountered. The present submechanism has been assembled from recent reaction rate compilations [10-14] with the intent that each of the elementary reactions should be included with the most accurate rate expression available. This mechanism was then tested extensively by comparisons with experimental results, such as the CO oxidation study of Dryer and Glassman [15] in a turbulent flow reactor. These same experimental results have been used in the past to test the $\mathrm{CO}-\mathrm{H}_{2}-\mathrm{O}_{2}$ submechanisms of hydrocarbon reaction mechanisms $[12,16]$, and the agreement between observations and results predicted by the present mechanism was excellent [9]. In common with virtually all kinetic modeling studies of $\mathrm{CO}$ and $\mathrm{H}_{2}$ oxidation, the present mechanism shows that most of the sensitivity in these systems is due to the reactions

$$
\begin{aligned}
& \mathrm{H}+\mathrm{O}_{2}=\mathrm{O}+\mathrm{OH} \\
& \mathrm{CO}+\mathrm{OH}=\mathrm{CO}_{2}+\mathrm{H}
\end{aligned}
$$

and that initiation of $\mathrm{CO}$ oxidation occurs through the reaction

$$
\mathrm{CO}+\mathrm{O}_{2}=\mathrm{CO}_{2}+\mathrm{O}
$$

and termination through the reaction

$$
\mathrm{CO}+\mathrm{O}+\mathrm{M}=\mathrm{CO}_{2}+\mathrm{M} \text {. }
$$

Methane Pyrolysis

Experimental kinetic studies of methane decomposition [17-20] have demonstrated how product species yields are influenced by operating conditions such as temperature, pressure and dilution by hydrogen or inert species. The present reaction mechanism accurately reproduces each of the observed trends, showing that 
methane is steadily converted to ethane via methyl radical recombination, and that ethane and ethylene are then dehydrogenated to produce acetylene. Observations that increased temperature improves acetylene selectivity are reproduced by the model, and heavier hydrocarbons including diacetylene, butadiene, benzene and polyaromatics result from successive addition and/or condensation reactions of acetylene, vinyl and acetylenic radicals, particularly

$$
\begin{aligned}
\mathrm{C}_{2} \mathrm{H}+\mathrm{C}_{2} \mathrm{H}_{2} & =\mathrm{C}_{4} \mathrm{H}_{3} \\
\mathrm{C}_{4} \mathrm{H}_{3} & =\mathrm{C}_{4} \mathrm{H}_{2}+\mathrm{H}
\end{aligned}
$$

Beyond this point, the model uses generalized components to describe the formation of heavier species with only a reduced number of reference components, as already described. Comparison between computed and experimental results is illustrated in Figure 1, using experimental data from Kunugi et al. [20] showing carbon selectivities of several species as functions of time in seconds. The reaction temperature is $1673 \mathrm{~K}$ with hydrogen dilution of $(3 / 1 \mathrm{~mol})$. In both the experiments and the simulations, the ethylene intermediate quickly achieves a steady value, followed at a later time by a maximum in acetylene selectivity. Then, with a much longer time constant, the acetylene level slowly decreases as it is converted to heavier hydrocarbons. Similar agreement at other reaction temperatures and diluent fractions indicates that the kinetic model can be used to optimize the engineering process and predict the influence of parameter variation on product yields. The mechanism includes the important reactions leading to heavier hydrocarbons, although in this model application, speciesspecific information for heavier species is not measured experimentally and a composite description of those species is satisfactory.

\section{Autoignition and Oxidation of Methane}

Oxidative coupling of methane to produce larger species including liquids often uses selected catalysts, both heterogeneous and homogeneous in nature. Choudhary et al. [21] studied the purely gas phase oxidation processes in order to obtain a better understanding of the different factors involved, such as the role played by steam in enhancing certain reactions. The results of those studies have been incorporated into the present mechanism, which explains the observed yields and selectivities of products including ethane, ethylene and other less important species. Additional studies $[22,23]$ of methane oxidation and autoignition under a variety of relatively high temperatures (approx. $1000-1400 \mathrm{~K}$ ) have further tested the model capabilities and applicability. 


\section{Partial Oxidation of Methane to Methanol}

Conversion of methane to liquid fuels has always been a major goal for better use of natural gas and has enormous economic potential importance. Experimental studies at relatively low pressures [24-26] and more recently at much higher pressures [27-29] have been the subject of recent mechanistic studies [30-33]. The present mechanism is based on this recent modeling work, all of which indicates that the key to high yields of methanol involves subtle differences in rates of reactions of methoxy and methylperoxy radicals. Methanol is produced by $\mathrm{H}$ atom abstraction from methane by $\mathrm{CH}_{3} \mathrm{O}$ or by

$$
\mathrm{CH}_{3} \mathrm{OO}+\mathrm{CH}_{3} \mathrm{OO}=\mathrm{CH}_{3} \mathrm{OH}+\mathrm{CH}_{2} \mathrm{O}+\mathrm{O}_{2} \quad \text { (R 401) }
$$

Methylperoxy radicals are formed from methane by the reactions

$$
\begin{aligned}
& \mathrm{CH}_{4}+\mathrm{R}=\mathrm{CH}_{3}+\mathrm{RH} \\
& \mathrm{CH}_{3}+\mathrm{O}_{2}=\mathrm{CH}_{3} \mathrm{OO}
\end{aligned}
$$

$\mathrm{CH}_{3} \mathrm{OO}$ leads to methoxy through two paths

$$
\text { and } \quad \begin{aligned}
\mathrm{CH}_{3} \mathrm{OO}+\mathrm{CH}_{3} \mathrm{OO} & =\mathrm{CH}_{3} \mathrm{O}+\mathrm{CH}_{3} \mathrm{O}+\mathrm{O}_{2} \\
\mathrm{CH}_{3} \mathrm{OO}+\mathrm{HO}_{2} & =\mathrm{CH}_{3} \mathrm{OOH}+\mathrm{O}_{2} \\
\mathrm{CH}_{3} \mathrm{OOH} & =\mathrm{CH}_{3} \mathrm{O}+\mathrm{OH}
\end{aligned}
$$

Several of these reactions, as well as the thermal decomposition reactions of methoxy and methylperoxy radicals, have significant temperature and pressure dependence. This complex reaction system is very well suited to computational modeling analysis, and the current mechanism has been used to examine this process with reasonable success. The importance of the alkylperoxy radical reaction sequences is evident and their inclusion in the mechanism represents a new feature not present in previous comprehensive mechanisms for small hydrocarbon combustion. Their inclusion makes the computational tool much more general and applicable to an entirely new class of important practical applications.

\section{Oxidation of Methanol}

Methanol has many combustion and chemical engineering applications and has been been the subject of numerous kinetic studies, with several detailed kinetic mechanisms [34-36]. The present mechanism was used to repeat these model calculations, but the $\mathrm{H}$ atom abstraction reactions were replaced by the formulations shown in Table I. Overall agreement with experimental results and with computed results of previous models showed reasonable agreement. The methanol oxidation mechanism is a particularly linear one, with $\mathrm{H}$ atom abstraction from $\mathrm{CH}_{3} \mathrm{OH}$ leading directly to formaldehyds and then $\mathrm{CO}$. 


\section{Oxidation of Formaldehyde}

Formaldehyde is produced during the oxidation of virtually all hydrocarbons, and it is particularly important as the major intermediate formed during methanol combustion [34]. However, its chemical analysis is often quite difficult to carry out when it is a combustion intermediate, so it is important to study its kinetics in experiments where formaldehyde is a primary fuel. Its oxidation at combustion conditions has been studied under shock tube [37] and turbulent flow reactor [38] conditions. The results of Hochgreb et al. [38] were used to validate the present reaction mechanism, with the model showing that formaldehyde oxidation proceeds primarily through $\mathrm{H}$ atom abstraction to produce formyl radicals, which then react with molecular oxygen or decompose thermally

$$
\begin{aligned}
& \mathrm{CH}_{2} \mathrm{O}+\mathrm{R}=\mathrm{HCO}+\mathrm{RH} \\
& \mathrm{HCO}+\mathrm{O}_{2}=\mathrm{CO}+\mathrm{HO}_{2} \\
& \mathrm{HCO}+\mathrm{M}=\mathrm{H}+\mathrm{CO}+\mathrm{M}
\end{aligned}
$$

\section{Ethane Pyrolysis}

Ethane pyrolysis has considerable industrial importance and has been studied extensively [39]. The most important product is ethylene, followed by the same general series of minor products as noted above from methane pyrolysis, including acetylene, propene, butadiene, benzene, styrene and naphthalene. Initiation takes place via

$$
\mathrm{C}_{2} \mathrm{H}_{6}(+\mathrm{M})=\mathrm{CH}_{3}+\mathrm{CH}_{3}(+\mathrm{M}) \text {. }
$$

$\mathrm{H}$ atom abstraction produces ethyl radicals which decompose to make ethylene. Addition of ethyl and vinyl radicals to ethylene leads to the $\mathrm{C}_{4}$ olefins and butadiene observed in experiments. The lumping of the structurally distinct butene isomers described above provides very satisfactory results when compared with observed total butene yields.

\section{Ethylene Pyrolysis}

Olefin pyrolysis has considerable importance in industrial processes, and olefins are common intermediates in most combustion environments. There have been many experimental and kinetic modeling studies of olefin pyrolysis [39-42], and the present model has been used to simulate a variety of these experiments. Some of the major features of the present model can be illustrated for the case of ethylene pyrolysis in a thermal reactor, studied by Kunugi et al. [41,42]. In these experiments, product selectivities of species including butadiene, butenes, benzene and cyclopentadiene were reported as functions of ethylene conversion at selected reactor temperatures. 
An example of comparison between computed and experimental results at $854 \mathrm{C}$ $(1127 \mathrm{~K})$ is shown in Figure 2 . Although the reactions producing benzene and cyclopentadiene are global rather than detailed steps, the overall agreement between computed species profiles and measured results is very good. The reaction mechanism indicates the most important reaction pathways leading to the principal product species. In pure ethylene, dimerization of ethylene leads to a radical pool of allyl and methyl radicals

$$
\begin{aligned}
& \mathrm{C}_{2} \mathrm{H}_{4}+\mathrm{C}_{2} \mathrm{H}_{4}=1-\mathrm{C}_{4} \mathrm{H}_{8} \\
& \text { 1-butene }=\mathrm{a}-\mathrm{C}_{3} \mathrm{H}_{5}+\mathrm{CH}_{3}
\end{aligned}
$$

followed by production of butadiene $\left(\mathrm{C}_{4} \mathrm{H}_{6}\right)$, a major product species in the experiments, through the sequence of reactions

$$
\begin{aligned}
& \mathrm{C}_{2} \mathrm{H}_{4}+\mathrm{C}_{2} \mathrm{H}_{3}=\mathrm{C}_{4} \mathrm{H}_{7} \\
& \mathrm{C}_{4} \mathrm{H}_{7}=\mathrm{C}_{4} \mathrm{H}_{6}+\mathrm{H}
\end{aligned}
$$

Other major products are cyclopentadiene, produced through two paths

$$
\begin{aligned}
& \mathrm{C}_{2} \mathrm{H}_{3}+\mathrm{C}_{4} \mathrm{H}_{6}=\mathrm{CPTD}+\mathrm{CH}_{3} \\
& \mathrm{C}_{4} \mathrm{H}_{7}+\mathrm{C}_{2} \mathrm{H}_{4}=\mathrm{CPTD}+\mathrm{H}_{2}+\mathrm{CH}_{3}
\end{aligned}
$$

and benzene, produced by

$$
\mathrm{CPTD}+\mathrm{C}_{2} \mathrm{H}_{4}=\text { Benzene }+\mathrm{CH}_{3}+\mathrm{H} \text {. }
$$

The last of these reactions are global steps, since there are unstable intermediate species that isomerize to lead eventually to the products indicated here.

\section{Ethane Oxidation}

Experimental data from jet stirred and static reactors [43,44] were simulated using the present mechanism with generally satisfactory results. Reaction pathways leading to ethylene oxide through addition of $\mathrm{O}_{2}$ to ethyl radicals, followed by ethylperoxy radical isomerization, are included in the mechanism and distinguish this mechanism from previous comprehensive mechanisms. In each of these simulations, ethylene is the most important product of partial oxidation.

\section{Ethylene Oxidation}

Ethylene oxidation has been examined frequently in combustion environments. Recent studies particularly well suited to kinetic modeling analysis include those in a tubular reactor [45], a jet stirred reactor [46,47], and turbulent flow reactor [48]. The present reaction mechanism provides good agreement with all of these experimental results. In addition to reactions important for pyrolysis already noted, $\mathrm{H}$ atom 
abstraction by $\mathrm{O}$ and $\mathrm{OH}$, and addition reactions of $\mathrm{OH}$ and $\mathrm{O}$ with ethylene are very important. Reactions of vinyl radicals that are of particular importance are

$$
\mathrm{C}_{2} \mathrm{H}_{3}+\mathrm{O}_{2}=\mathrm{CH}_{2} \mathrm{O}+\mathrm{HCO}
$$

and

$$
\mathrm{C}_{2} \mathrm{H}_{3}+\mathrm{O}_{2}=\mathrm{C}_{2} \mathrm{H}_{2}+\mathrm{HO}_{2}
$$

In spite of the good agreement between computed and experimental results, sensitivity analyses show that there are still many uncertainties remaining in the reaction mechanisms for ethylene and larger olefin and other unsaturated species. In particular, the rates and pressure dependence of the addition channels are not well established and involve paths among different activated complexes. As a result, considerable further work is needed to improve current reaction mechanisms in these areas.

\section{Acetaldehyde Oxidation}

Experimental and modeling studies of acetaldehyde oxidation have been used to focus attention on lower temperature phenomena, particularly the negative temperature coefficient and cool flame phenomena [49-52]. The present reaction mechanism was used to reproduce previous modeling results, with the important difference that the $\mathrm{H}$ atom abstraction rules summarized above and in Table I [9] were used for reactions of acetaldehyde. The computed results were essentially the same as in previous modeling analyses, indicating that the similarity rules for $\mathrm{H}$ atom abstraction can be used with acceptable accuracy in modeling complex systems.

\section{$\mathrm{C}_{1}-\mathrm{C}_{4}$ Ignition in Shock Tubes}

Shock tube pyrolysis and ignition have been used frequently in studies of hydrocarbon kinetics. Depending on the degree of dilution, fuel type and other conditions, individual elementary reactions can be studied and reaction rates determined, or entire reaction mechanisms can be evaluated. In most cases, reaction takes place at elevated temperatures (above $1100 \mathrm{~K}$ ) and pressures between 3 and 10 bar. Shock tube conditions are particularly useful in testing reaction mechanisms since this is the only common environment in which initiation reactions are very important. The ignition process is usually characterized as a relatively long initiation and radical pool growth period, followed by a rather short period of ignition in which all of the fuel is converted to $\mathrm{CO}, \mathrm{CO}_{2}$ and $\mathrm{H}_{2} \mathrm{O}$. For hydrocarbon fuels, the key to the overall rate of reaction is the balance in the $\mathrm{H}$ atom concentration [7]. The most important chain branching reaction in these systems converts one $\mathrm{H}$ atom into two $\mathrm{O}$ and $\mathrm{OH}$ radicals by

$$
\mathrm{H}+\mathrm{O}_{2}=\mathrm{O}+\mathrm{OH}
$$


Therefore, reactions that increase $\mathrm{H}$ atom levels accelerate ignition while reactions that consume $\mathrm{H}$ atoms slow the overall rate of ignition.

The present reaction mechanism was tested by comparisons between computed results and shock tube selected from the experimental literature. A particularly useful series of shock tube ignition studies was carried out by Burcat et al. [53], in which nalkanes from methane to n-pentane were examined. In addition to the range of related fuels, the initial concentrations of the fuel and oxygen were close to those of fuel/air mixtures relevant to practical combustion systems, rather than the extremely dilute mixtures often used in shock tube studies. The work of Burcat et al. has been used extensively in past validations of detailed reaction mechanisms [54-56].

Experimental ignition delay times were defined as the time interval between arrival of the reflected shock wave and the first observable pressure rise, with the results for methane, ethane, propane and n-butane as the different symbols in Figure 3. At each temperature, methane is much slower to ignite than the other fuels, which are all quite nearly equal in ignition rate. However, ethane ignition is very slightly faster than either propane or n-butane.

The present reaction mechanism was used to simulate these shock tube experiments, with the computed results indicated as lines in Fig. 3. Overall the agreement with the measured data is excellent, both with respect to the variations between the different fuels as well as the slope (or equivalent overall activation energy) or temperature dependence for each fuel. The computed results for ethane, propane and $\mathrm{n}$-butane predict slightly faster ignition than is observed experimentally, and the computed ignition delay times for ethane are approximately equal to those for propane and n-butane, although the experiments indicate that ethane ignition is slightly faster than that of the larger n-alkanes. Still, the overall trends and actual numerically predicted values are accurately reproduced by the present reaction mechanism.

\section{Shock Tube Ignition of Methanol}

The shock tube ignition of methanol was investigated in the same manner as for the $\mathrm{C}_{1}-\mathrm{C}_{4} \mathrm{n}$-alkanes, using experimental results reported by Bowman [57]. These experiments also have been used widely in testing detailed reaction mechanisms [e.g., 16] and provide the same types of demands on the reaction mechanism as those described above in the case of the $n$-alkanes. Bowman defined ignition in terms a maximum in the observed chemiluminescence from the reaction

$$
\mathrm{CO}+\mathrm{O}+\mathrm{M}=\mathrm{CO}_{2}+\mathrm{M}
$$


Comparisons between measured data and computed results showed agreement comparable to that for the $\mathrm{C}_{2}-\mathrm{C}_{4} \mathrm{n}$-alkanes above, with the computed results slightly faster than the measurements by factors of about $2-6$ over the range of temperatures studied.

\section{Conclusions}

A detailed chemical kinetic model has been developed which accurately describes pyrolysis, ignition and oxidation of many small hydrocarbon fuels over a wide range of experimental conditions. Formation of larger intermediate and product species including benzene, butadiene, large olefins, and cyclopentadiene has been treated in a semi-empirical manner. The reaction mechanism has been tested for conditions that do not involve transport and diffusional processes, including plug flow and stirred reactors, batch reactors and shock tubes. The present kinetic model and its validation differ from previous comprehensive detailed reaction mechanisms in two important ways. First, in addition to conventional combustion data, experiments more commonly associated with chemical engineering problems such as oxidative coupling, oxidative pyrolysis and steam cracking have been used to test the reaction mechanism, making it even more general than previous models. In addition, $\mathrm{H}$ atom abstraction and some other reaction rates, even for the smaller $C_{2}, C_{3}$ and $C_{4}$ species, are treated using approximations that facilitate future extensions to larger fuels in a convenient manner. Constructed in a modular fashion, the mechanism can be revised as needed by replacing any submodel with an improved treatment; this is particularly relevant in the case of the global submodels leading to aromatic and other heavier hydrocarbon products. The present effort has also identified a large number of kinetic studies which can be used in future tests of kinetic models for small and intermediate size hydrocarbon fuels.

\section{Acknowledgments}

Those portions of this work that were carried out at Livermore were supported by the Gas Research Institute under contract No. 5091-260-2271 and by the U. S. Department of Energy, Office of Basic Energy Sciences, Division of Chemical Sciences and were carried out at the Lawrence Livermore National Laboratory under the auspices of the U.S. Department of Energy under contract No. W-7405-ENG-48. 


\section{References}

1. Westbrook, C.K., Adamczyk, A.A., and Lavoie, G.A., Combust. Flame 40, 81(1981).

2. Harris, S.J., and Wiener, A.M., Combust. Sci. Technol. 31, 155 (1983).

3. Westbrook, C. K., Pitz, W. J., and Leppard, W. R., Society of Automotive Engineers paper SAE 912314 (1991).

4. Miller, J. A., and Bowman, C. T., Prog. Energy Combust. Sci. 15, 287 (1989).

5. Dente, M., Pierucci, S., Ranzi, E., and Bussani, G., Chem. Eng. Sci. 47, 2629 (1992).

6. Ranzi, E., Dente, M., Costa, A., and Bruzzi, V., Ing. Chim. Ital. 24, 2 (1988).

7. Westbrook, C. K., and Dryer, F. L., Prog. Energy Combust. Sci. 10, 1 (1984).

8. Chevalier, C., Pitz, W. J., Warnatz, J., Westbrook, C. K., and Melenk, H., TwentyFourth Symposium (International) on Combustion, p. 93, The Combustion Institute, Pittsburgh (1992).

9. Ranzi, E., Sogaro, A., Gaffuri, P., and Pennati, G., Combust. Sci. Technol., in press (1993).

10. Warnatz, J., Rate coefficients in C/H/O system. Ch. 5 in Combustion Chemistry, W. C. Gardiner, Jr., Ed., Springer-Verlag, New York (1984).

11. Tsang, W., and Hampson, R.F., J. Phys. Chem. Ref. Data 15, 1087 (1986).

12. Yetter, R.A., Dryer, F.L., and Rabitz, H., Combust. Sci. Technol. 79, 94 (1991).

13. Baulch, D. L., Cobes, C. J., Cox, R. A., Esser, C., Frank, P., Just, T., Kerr, J. A., Pilling, M. J., Troe, J., and Walker, R. W., J. Phys. Chem. Ref. Data 21, 411 (1992).

14. Smooke, M. D., AIChE Journal 32, 1233 (1986).

15. Dryer, F.L., and Glassman, I., Fourteenth Symposium (International) on Combustion, p. 987, The Combustion Institute, Pittsburgh (1972).

16. Westbrook, C.K., Creighton, J., Lund, C., and Dryer, F.L., J. Phys. Chem. 81, 2542(1977).

17. Chen, C.J., Back, M.H., and Back, R.A., Industrial and Laboratory Pyrolysis, ACS Symposium Ser. 32, Ch. 1, Am. Chem. Soc., Washington, D. C. (1976).

18. Pichler, H., Chem. Eng. Progr. 61, 63 (1966).

19. Holmen, A., Rokstad, O.A., and Solbakken, A., Ind. Eng. Chem. Proc. Des Dev. 15, 439 (1976).

20. Kunugi, T., Tamura, T., and Naito, T., Chem. Eng. Progr. 57, 11, 43 (1961).

21. Choudhary, R.V., Choudhary, S.P., and Raiput, A.M., A.I.Ch.E.J. 37, 915 (1991).

22. Rotzoll, Combust. Sci. Technol. 47, 275 (1986).

23. Dagaut, P., and Cathonnet, M., J. Chim. Phys. 87, 221 (1990).

24. Antonik, S., Bull. Soc. Chim., 3296 (1973).

25. Pelini, N., and Antonik, S., Bull. Soc. Chim., 2735 (1974). 
26. Chou, T.C., and Albright, L.F., Ind. Eng. Chem. Proc. Des. Dev. 17, 454 (1978).

27. Hunter, N.R., VI Int. Symp. Alcohol Fuels Technol. Ottawa, Canada (1984).

28. Gesser, H.D., Hunter, N.R., and Morton, L.A., US Patent 4618732 (1986).

29. Yarlagadda, P.S., Morton, L.A., Hunter, N.R., and Gesser, H.D., Ind. Eng. Chem. Res. 2, 252 (1988).

30. Gallone, A.R., and Zaccaro, M., Thesis, Politecnico di Milano, Italy (1986).

31. Vedeenev, V.I., Goldemberg, M.Y., Gorban, N.I. and Teitelboim, A., Kinet. Katal. 29 (1), 7 (1988).

32. Vedeenev, V.I., Goldemberg, M.Y., Gorban, N.I. and Teitelboim, A., Kinet. Katal. 29 (6), 1291 (1988).

33. Bistolfi, M., Giusti, A., Dente, M., and Ranzi, E., Int. Symp. Alcohol Fuels, Firenze, Italy (1991).

34. Westbrook, C. K., and Dryer, F. L., Combust. Sci. Technol. 20, 125-140 (1979).

35. Norton, T.S., and Dryer, F.L., Combust. Sci. Technol. 63, 107 (1989).

36. Egolfopoulos, F.N., Du, D.X., and Law, C.K., Comb. Sci. Technol., in press (1993).

37. Dean, A. M., Johnson, R.L., and Steiner, D.C., Combust. Flame 37, 41 (1980).

38. Hochgreb, S., Yetter, R.A., and Dryer, F.L., Twenty-Third Symposium (International) on Combustion, p. 171, The Combustion Institute, Pittsburgh (1990).

39. Dente, M., Ranzi, E., and Goosens, A. G., Comp. Chem. Engng. 3, 61 (1979).

40. Kinney, R. E., and Crowley, D. J., Ind. Eng. Chem. 46, 258 (1954).

41. Kunugi, T., Sakai, T, Soma, K., and Sasaki, Y., Ind. Eng. Chem. Fund. 8, 374 (1970).

42 Kunugi, T., Sakai, T, Soma, K., and Sasaki, Y., Ind. Eng. Chem. Fund. 9, 314 (1970).

43. Dagaut, P., Cathonnet, M., and Boettner, J.C., J. Phys. Chem. 23, 437 (1991).

44. Baldwin, R.R., Hopkins, D.E., and Walker, R.W., Trans. Farad. Soc. 66, 189 (1970).

45. Cathonnet, M., Gaillard, F., Boettner, J.C., Cambray, P., Karmed, D., and Bellet, J.C., Twentieth Symposium (International) on Combustion, p. 819, The Combustion Institute, Pittsburgh (1984).

46. Dagaut, P., Cathonnet, M., Boettner, J.C., and Gaillard, F., Combust. Flame 71, 295 (1988).

47. Westbrook, C.K., Thornton, M.M., Pitz, W.J., and Malte, P.C., Twenty-Second Symposium (International) on Combustion, p. 863, The Combustion Institute, Pittsburgh (1988).

48. Westbrook, C.K., Dryer, F.L., and Schug, K.P., Nineteenth Symposium (International) on Combustion; p. 153, The Combustion Institute, Pittsburgh (1982).

49. Baldwin, R.R., Matchan, M.J., and Walker, R.W., Combust. Flame 15, 109 (1970).

50. Kaiser, E.W., Westbrook, C.K., and Pitz, W.J., Int. J. Chem. Kinet. 18, 655 (1986). 
51. Cavanagh, J., Cox, R.A., and Olson, G., Combust. Flame 82, 15 (1990).

52. DiMaio, F.P., Lignola, P.G., and Talarico, P., Combust. Sci. Technol. in press (1992).

53. Burcat, A., Scheller, K., and Lifshitz, A., Combust. Flame 16, 29-33 (1971).

54. Westbrook, C. K., and Pitz, W. J., pp. 287-293 in Shock Waves and Shock Tubes, D. Bershader and R. Hanson, eds., Stanford University Press, Stanford, CA, 1986.

55. Westbrook, C. K., Combust. Sci. Technol. 20, 5-17 (1979).

56. Pitz, W. J., Westbrook, C. K., Proscia, W.M., and Dryer, F. L., Twentieth Symposium (International) on Combustion, pp. 831-843, The Combustion Institute, Pittsburgh, 1984.

57. Bowman, C. T., Combust. Flame 25, 343-354 (1975). 


\section{Figure Captions}

1. Carbon selectivities for methane pyrolysis at $1673 \mathrm{~K}$, shown as functions of reaction time in seconds. Methane is diluted $(3 / 1 \mathrm{~mol})$ by hydrogen.

2. Ethylene pyrolysis at $1127 \mathrm{~K}$, showing cyclopentadiene and benzene selectivity (in percent) plotted as functions of ethylene conversion.

3. Calculated and experimentally measured [11] ignition delay times for $C_{1}-C_{4}$ n-alkanes in $\mathrm{O}_{2}$ / Ar mixtures. 


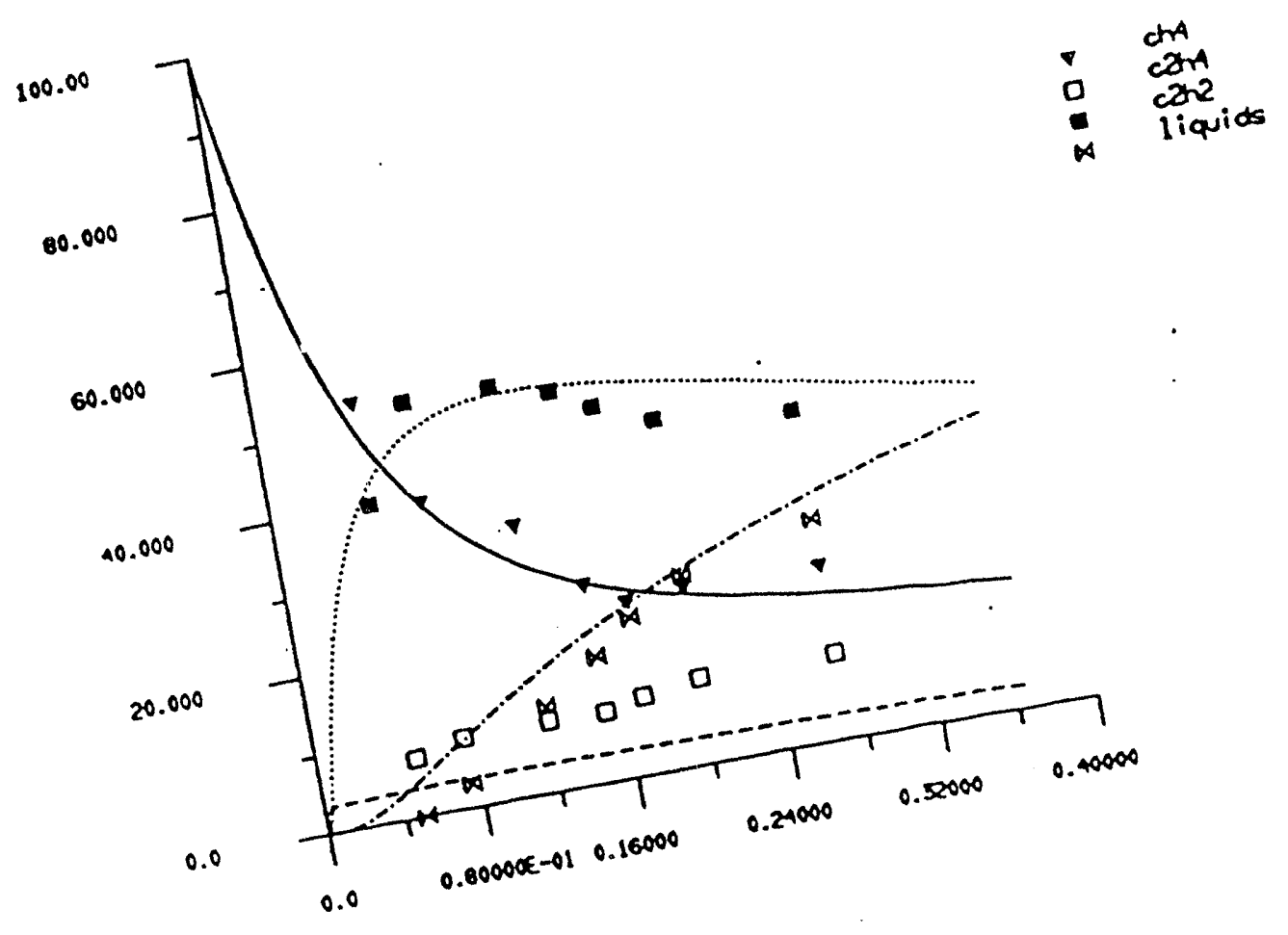

Figure 1 


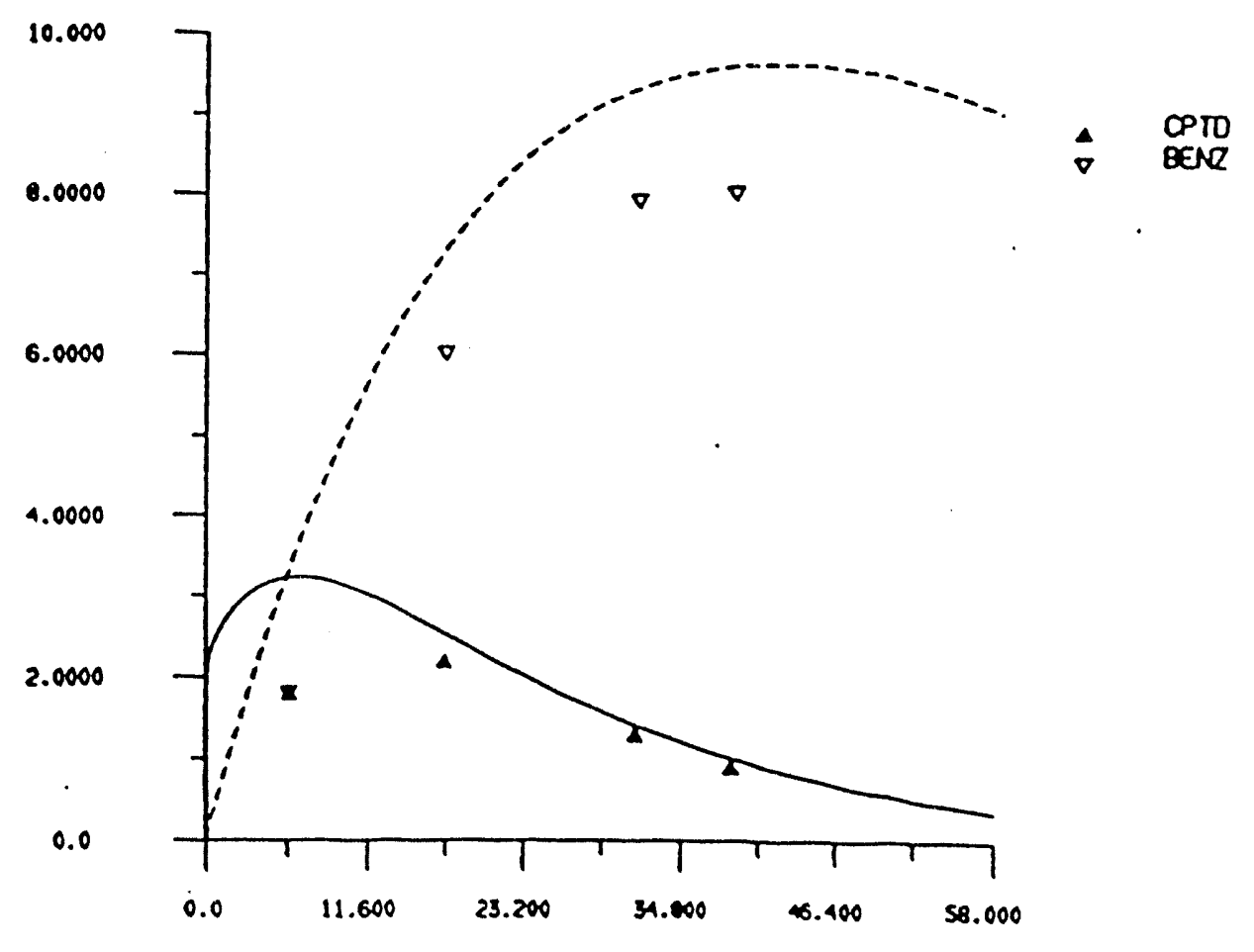

Figure 2 


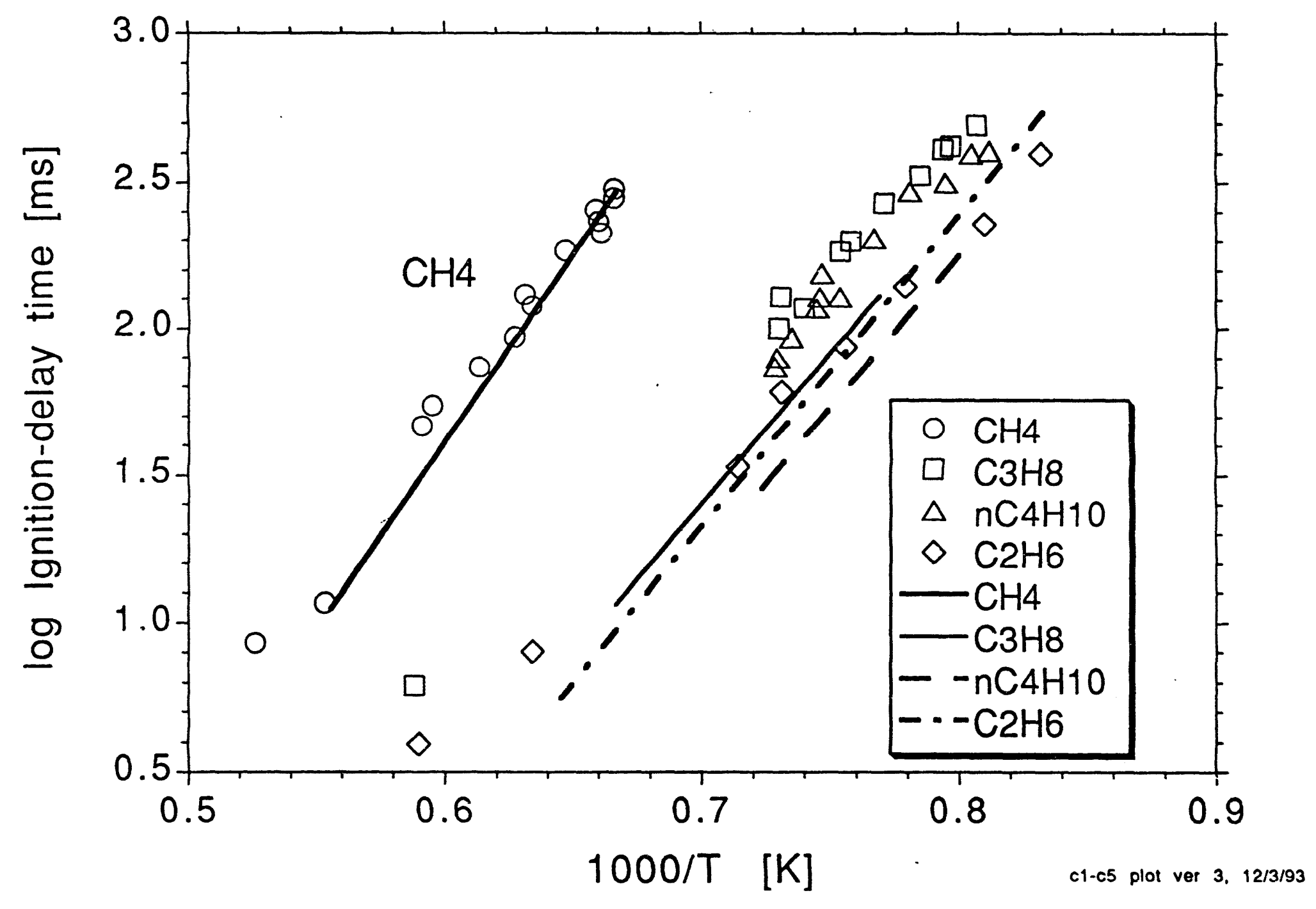




\begin{tabular}{|c|c|c|c|}
\hline $\begin{array}{l}\text { Radical } \\
\mathrm{R}\end{array}$ & $\begin{array}{l}\text { Compound } \\
\mathrm{RH}\end{array}$ & $\begin{array}{c}\text { freq.factor } \\
\mathrm{A}^{0}{ }_{\text {Tef, } \mathrm{R}^{\prime}}\end{array}$ & $\begin{array}{c}\text { act.energy } \\
E^{0}{ }_{\text {ref, }}\end{array}$ \\
\hline $\mathbf{H}$ & $\mathrm{H} 2$ & $.1585 \mathrm{E}+11$ & 10500.0 \\
\hline $\mathrm{CH} 3$ & $\mathrm{CH} 4$ & $.2884 E+09$ & 11500.0 \\
\hline $\mathrm{C} 2 \mathrm{HS}$ & $\mathrm{C} 2 \mathrm{H} 6$ & $.1698 E+09$ & 14200.0 \\
\hline NP & C $3 \mathrm{H} 8$ & $.1000 \mathrm{E}+09$ & 13400.0 \\
\hline IP & С $3 \mathrm{H} 8$ & $.1000 \mathrm{E}+09$ & 14700.0 \\
\hline NBP & NBUTA & $.1000 \mathrm{E}+09$ & 13700.0 \\
\hline NBS & NBUTA & $.1096 \mathrm{E}+09$ & 14700.0 \\
\hline IBP & IBUTA & $.9333 E+08$ & 13800.0 \\
\hline $\mathrm{IBT}$ & BBUTA & $.5012 E+08$ & 15000.0 \\
\hline VIN & $\mathrm{C} 2 \mathrm{H} 4$ & $.5012 E+09$ & 11500.0 \\
\hline C5H7 & PTISO & $.1995 \mathrm{E}+09$ & 22500.0 \\
\hline C4HSP & BUTAD & $.1995 \mathrm{E}+09$ & 11200.0 \\
\hline ALVI & С $3 \mathrm{H} 6$ & $.1995 \mathrm{E}+09$ & 11200.0 \\
\hline ALP & C3H 6 & $.1778 \mathrm{E}+09$ & 22550.0 \\
\hline C4H7P & BUT12 & $.1000 E+09$ & 13500.0 \\
\hline C4H7S & BUT12 & $.2512 E+09$ & 22550.0 \\
\hline IC4H7 & & $2512 E+09$ & 22550.0 \\
\hline $\mathrm{C} 2 \mathrm{H}$ & С2H2 & $3020 \mathrm{E}+09$ & 12000.0 \\
\hline $\mathrm{C} 4 \mathrm{H}^{3}$ & C4H4 & $.3020 E+09$ & 12000.0 \\
\hline $\mathrm{OH}$ & 120 & $2951 \mathrm{E}+10$ & 3700.00 \\
\hline HO2 & $\mathrm{H} 2 \mathrm{O} 2$ & $3981 E+09$ & 19000.0 \\
\hline MEOO & MEOOH & $.5623 E+09$ & 19500.0 \\
\hline $\mathrm{CH} 3 \mathrm{O}$ & $\mathrm{CH} 3 \mathrm{OH}$ & $3162 E+09$ & 8250.00 \\
\hline CH2OH & $\mathrm{CH} 3 \mathrm{OH}$ & $2089 E+09$ & $\begin{array}{l}16350.0 \\
19500.0\end{array}$ \\
\hline $\begin{array}{l}\text { HCO } \\
\text { ETDO }\end{array}$ & $\begin{array}{l}\text { CH2O } \\
\text { ETOOH }\end{array}$ & $5623 E+09$ & 19500.0 \\
\hline $\mathrm{CHBCO}$ & MECHO & $.1000 \mathrm{E}+10$ & 21300.0 \\
\hline R2CHO & MECHO & $.1698 E+09$ & 18500.0 \\
\hline RACET & ACETO & $.1698 \mathrm{E}+09$ & 18500.0 \\
\hline 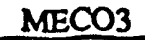 & PERAC & +09 & 12000.0 \\
\hline
\end{tabular}

Table I

\begin{tabular}{|c|c|c|}
\hline H-Type & AC & $\begin{array}{r}\text { EC } \\
\text { cal/mole }\end{array}$ \\
\hline 0 & 1.00 & 0.0 \\
\hline 1 & 1.00 & -2600.0 \\
2 & 1.00 & -3900.0 \\
3 & 7.00 & 1350.0 \\
4 & 1.75 & 4000.0 \\
5 & 5.00 & 9800.0 \\
6 & 0.40 & -7650.0 \\
7 & 1.00 & 4300.0 \\
8 & 4.00 & -4500.0 \\
9 & 0.50 & -1000.0 \\
\hline
\end{tabular}

Table II 

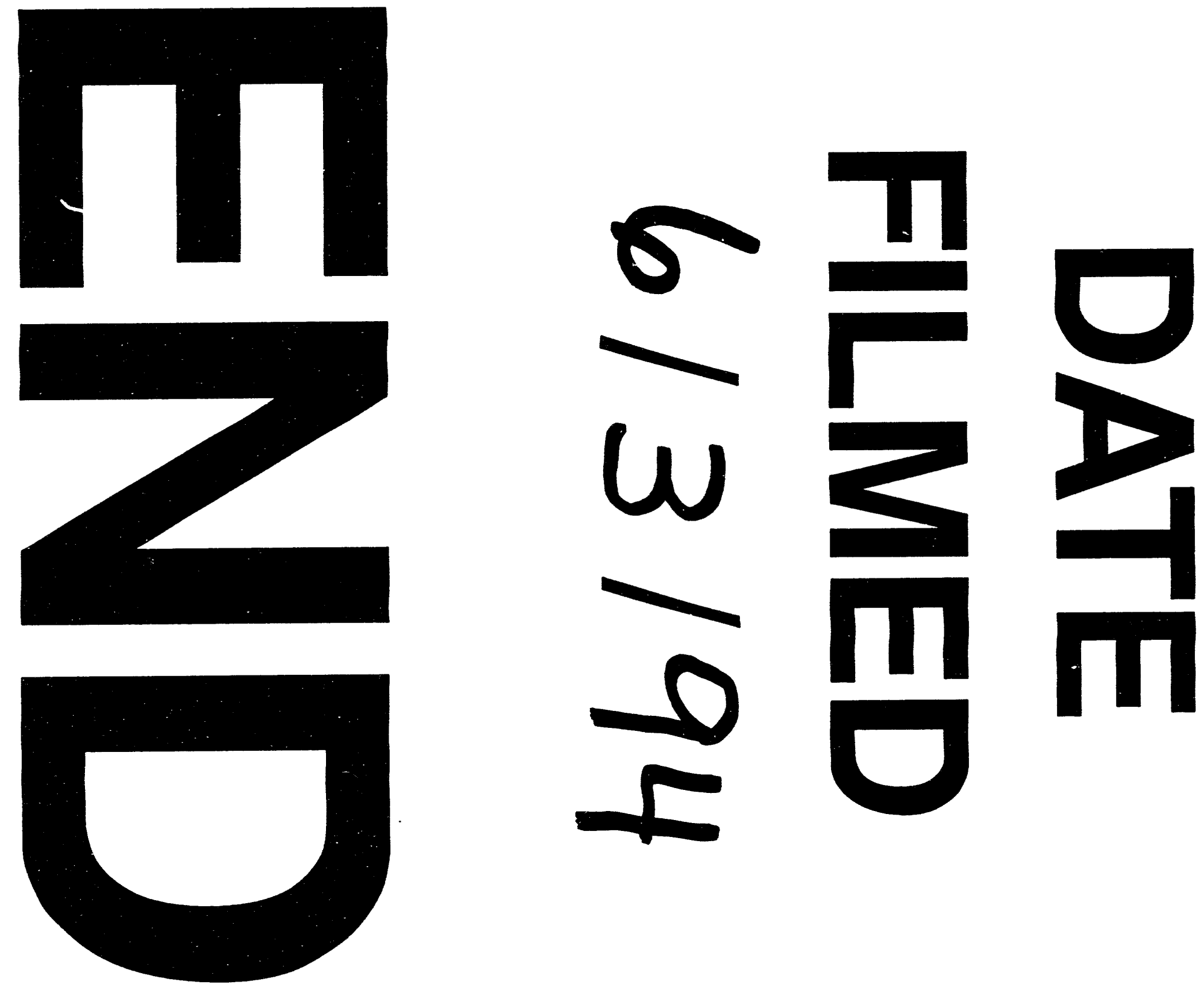
